This report was prepared as an account of work sponsored by an agency of the United States Government. Neither the United States Government nor any agency t'sereof, nor any oi the:r employees, makes any warranty, express or implied, or assumes any legal liability or respon ifbility for the accuracy, completeness, or usefulness of any information, apparatus, product, or process disclosed, or represents that its use would not infringe privately owned rights. Reference herein to any specific commercial product, process, or service by trade name, trademark. manufacturer, or otherwise does not necessarily constitute or imply its endorsement, recorimendation, or favoring by the United States Go unment or any agency thereof. The views and opinions of authors expressed herein do not necessarily state or reflect those of the United States Government or any agency thereof.

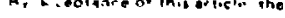

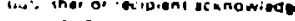

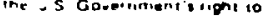

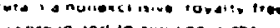
averno ind to article

\section{RADIO FREQUENCY VACUUM FEEDTHROUGHS FOR HIGH-POWER ICRF HEATING APPLICATIONS}

\section{T. L. OWENS," F. W. BAITY, D. J. HOFFMAN, J. H. WHEALTON}

CONF-850310--117

DE85 016391

\begin{abstract}
Frequenily, high-power pulsed ion cyclotron range of frequency experiments are limired by breakdown at the vacuum feedthrough. This paper desrribes the development and testing of vacuum feedthroughs to increase both reliability and capability. The ultimate goal of the program is to develop a continuous-wave feedthrough for the next generation of fusion experiments. A feedthrough concept eurrently under investigation consists of a simple, cylindrical alumina ceramic brazed between tapered coaxial conductors. A prototype has been tested to voltage levels in excess of $100 \mathrm{kV}$ for $100-\mathrm{ms}$ pulses and $70 \mathrm{kV}$ for $5-\mathrm{s}$ pulses at $28 \mathrm{MHz}$ Insertion-voltage-standing-wave ratios are $<1.15: 1$ for frequencies below $450 \mathrm{MHz}$. An upgraded water-cooled version being fabricated for use on TEXTOR will be described.
\end{abstract}

\section{INTRODUCTION}

Radio frequency ( $r$ ) heating of fusion plasmas in the ion cyclotron range of frequencies (ICRF) is now being widely applied to fusion experiments around the world. ${ }^{1-3}$ It is currently envisioned that fusion reactors will use this method to supplemeat ohmic heating and neutral beam heating. Puwer levels ane now in the multimegawatl range where state-of-the-art lechniques must be used to handle high voltages and curreats at radio frequencies. The barrier between the pressurized transmission line and the evacuated transmission line is a particularly crucial component because its failure affects not oniy the if system but also the entire machine vacuum integrity in many circumstances. This component has also been the weak link in voltage handling for some contemporary puised experiments. The potential problems it the feedthrough are compounded by operation approaching steady-state, is will be encountered in the next generation of fusion experiments.

This paper describes the program at the Oak Ridge National Luboratory (ORNL) to develop and (test feedthroughs for present-day and future fusion applications.

Research sponsored by the Office of Fusion Energy, U.S. Departmeat of Enc:gy, under Contrat No. DE-ACOS.8\$OR21400 witi Martin Marictla Energy Systems, lnc.

"Mi:Donnell Duuglas Astronzuties Company, Consultant to O2k Ridlge Nisional Liboraton.
A feedthrough development program has been under way at the Princeton Plasma Physics Laboratory for a number of years." Their elforts have led to the sucoessiul developtreat of a high-powcr feedthrough used in the ICRF heating experiments on the Princeton Large Toras (PLT). The FL:feedthrough uses a conical cermic barrier between inne: and outer cosxial conductors. The conductors are shaped primarily to reduce the component of the electric freld aloris the surface of the ceramic. The present paper describes an alternative concept that uses a cylindrical ceramic bartict brazed between tapered inner and outer coexisas conduetors. In this configutation, the clectris field along the ceranic surface can also be made quite sme!l. In addition, care thas been taken to maintain a constant characteristic impedance along the length of the feedthrough by proper adjustment of the upered angles of the conductors. This feature minimizes the insertion-voltuge-standing-wave ratio (IVSWR) and eliminates interaal reflections. The design affords the use of relatively simple fabrication techniques, and it can be easily adapted to long-pulse or continuous wave $(\mathrm{cw})$ use.

\section{FEEDTHIROUGH CONCEPT}

A simplified schematic of the feedthrough concept $r$ shown in Fig. 1. Contours of constant posential have bee: superimposed on the figure. ${ }^{5}$ In this case, the ceramic barrier is much longer than its diameier. This permits the construction of very gradual tapers on the inner and outer conductors. which in turn produces potential contours that are nearly parallel to the surface of the ceramic The electric field $(\vec{\nabla} \phi)$ is censequently near'y perpendicular to the surface of the ceramic. The possibility of surface breakdewn can thereby be substantially reduced or climinaled altogether.

A constant characteristic impedance results from the use of the straight tapers on inner and outer ccnductors. The value of the characteristic impedance for tapered lines is found approximately from

$$
Z_{i}=\sqrt{\frac{L_{Q}}{C_{l}}}=\frac{1}{2 \pi} \sqrt{\frac{\mu}{E}} \operatorname{Sn}\left\{\frac{\tan \left(\frac{\theta_{2}}{2}\right)}{\tan \left(\frac{\theta_{1}}{2}\right)}\right]
$$




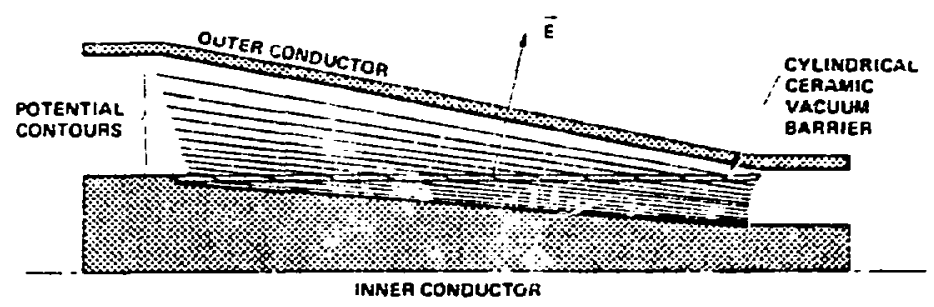

FIG. 1. ORNL fexithrough concept.

where $L_{p}$ is the in .. cta: . a pe: unu length, $C_{R}$ is the capacitance per unit leng:', and $\eta_{2} \mathrm{a}-1 \theta_{1}$ are the angles made by the outer and inner condictar:, respectively, relative to the axis of the feedthrongi. Ti. , icature is particularly important for antennas tis it place the impedance-matcining components inside ...: acuum system in an integrated fashion with the anten " - "idia:ing " : $\pi$ int. Examples of such antennas include the rescalant dc ...ie ksp. ${ }^{6}$ now being developed at ORNL, and the U-slot antenna, proposed by the MeDonnell Douglas Astronautios Company. In these cases, the vacuum feodthrough is placed at the impedance-matched input (usually 50 ohms) to the antenna system where reflected power has been minimized. In this position it is important that the characteristic impedence of the feedthrough closely match the characteristic impedance of the transmission line to which it is connected, in order to minimize the IVSWR. The IVSWR of a feedthrough that is short compared to a wavelength is given approximately by

$$
s_{1}=\frac{a+b}{a-b} \text {. }
$$

where

$$
\begin{aligned}
& c=\left\{\downarrow+\left[\beta \mathrm{Q}\left(\frac{Z_{1}}{Z_{0}}+\frac{Z_{0}}{Z_{1}}\right)\right]\right\}^{2 / 2} \\
& b=\left\{\beta Q\left(\frac{Z_{1}}{Z_{0}}-\frac{Z_{0}}{Z_{i}}\right)\right] .
\end{aligned}
$$

with $S=2 \pi / \lambda, \&$ the feedthrough electrical length, $Z$ the fecthrough's characteristic impedance, and $Z_{0}$ the characteris:ic impedance of the transmission line. As an example. for a feedthrough that has a characteristic impedance of 100 uhm, has a line length of $\lambda / 4 \pi$, and is conrected to SO-ohm transmission line terminating in 50 chms, the IVSWR is approximately 1.9. Peak power handling for the transmission system would be reduced by a facror of 1.9 unless additional maltching equipratent were used to compensate for the fecdthrough mismatch. A 50-ohm feedthrough, on the othe. harid. wouid nor degrade transmission performance in this situation.
Under normal operating conditions voltage and current at the impedance-matched point are modest even for power levels on the order of a megawatt $(V=10 \mathrm{kY}, I=200 \mathrm{~A}$ at I MW). Feedthroughs placed at this point, however, will still need to be designed for much higher voitages and currents in order to handle occasional accidents or fault conditions that could result in large mismatches.

\section{PRELIMINARY TISTING}

A test of the general coucept was ferformed using the foedthrough diagrammed in Fig. 2 For this test version of the feedihrough, input and output connoctions are 33 in The large diameter portion of the foedthrough has a 9-in. inside diameter. The water jacket shown in Fif 2 was not used in the tests described bere. Analyzis of potential contours indicates that the wave fields are directed at 3pproximately a $45^{\circ}$ angle to the surfase of the ceramic. The impedance of the feedthrough bas been designed to be close to 50 ohms. Constancy of impedance has not been optimiized for this teat. The measured IVSWR is less then 1.15:1 for frequencies below about $400 \mathrm{MHz}$

High-vollage of testing was acoomplished using the experimental apparatus shown schematically in Fig. 3. Basically, the feedthrough is placed at the end of a section of coaxial transmission line that is somewhat greater than $\mathrm{N} / 4$. The feedthrough is left open circuited at the end of this ine seetion so that the input impodance is inductive. A capacitive - Luning circuit inpedance matcies this indectunce and the small equivalent resistance of the transmiscion line to $\mathrm{J}$ s0-ohm cosxial transmission line. A transmitter capable of $100 \mathrm{~kW}$ of $\mathrm{cw}$ operation over the frequency range 3 to $30 \mathrm{MHz}$ drives the circuitis. The capacitive tuner is capable of impedance matching over the frequeacy range 20 to 30 MHz Besause of the $\lambda / 4$ transformer section, high voltages are produced at the feodthrough cnd. whereas iow voisages are mainbined at the capacitive tuner. Voltages expected at the feedthrough can be estimated from

$$
\left.\nu^{2}=\frac{\$ P Z_{0}^{2}}{R} \mid 2-\frac{1}{2 B} \sin (2 B P)\right\}^{-1}
$$




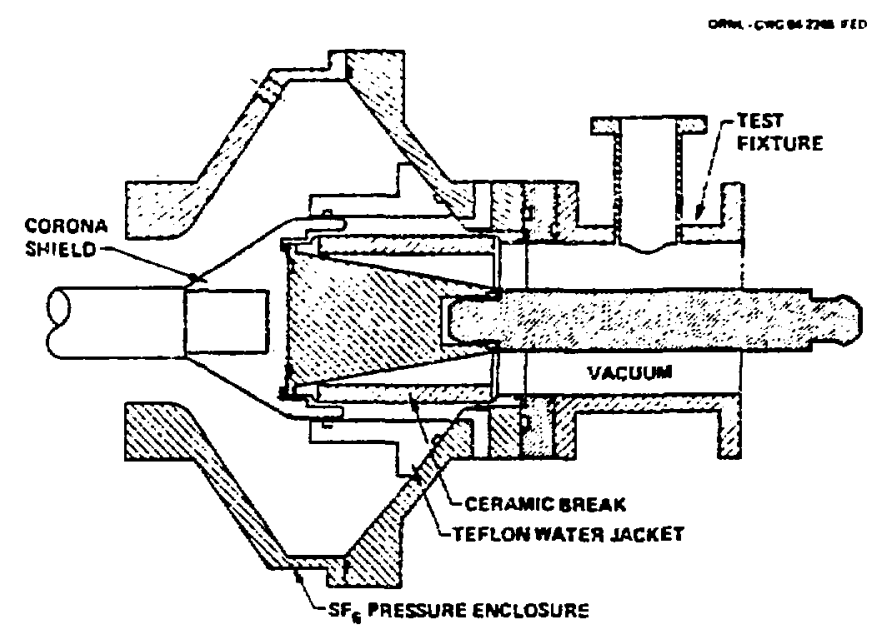

FIG. 2. Preliminary test version of the ORNL feedihrough.

OnNL-Oma es 2ase fED

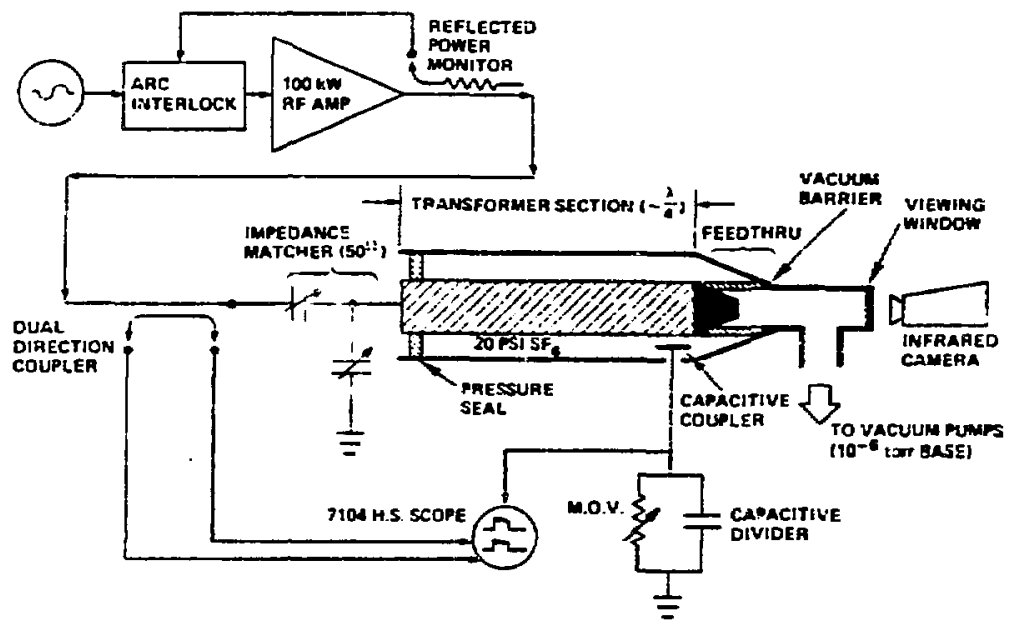

FIG. 3. High volta|se if test stand schematic. 
where $P$ is the forward puwer and $R$ is the equivalent series iesistance per unit length within the $\mathrm{A} / 4$ transformer sectiun. In prastice, the $\lambda / 4$ section is mule of aluminum so that the equivalent series resistance $R_{p}$ at its input $(R \cdot \Omega)$ is approximately equal to that of the parallel capacitor $\left\{R_{q}=\right.$ 0.02 ohms) so that half of the power from the transmitter is dissipated in the capucitur and half in the transformer sectwon. From Eq. (3), at a frequency of $25 \mathrm{MHz}$ and for $Q=$ $\lambda / 4=300 \mathrm{~cm}, Z_{0}=50$ ohms, and $R=7.5 \times 10^{-5}$ ? $/ \mathrm{cm}$, we find $v^{2}=4.4 \times: 9^{5} P$. For example, to produce $100 \mathrm{kV}$ at the feedthrough under these circumstances requires approximately $23 \mathrm{~kW}$ into the transformer section or $46 \mathrm{~kW}$ into the copacitive turer. These estimates are within a few percent of what was measured experimentally.

In the tests, a calibrated capacitive voltage probe was used to monitor the voltage at the feedthrough, as indicated schematically in Fig. 3. Forward power into the tuning circuit wis monitored using a directional coupler (also shown in Fig. 3). Drive power to the transmitter could be cut off in is few microseconds using an electronic attenustor in the drive circuitry. The attenuator was triggered on detection of excessive reflected power is protect components in the event of un arc.

The feedthrough was conditiontd by refeatedly breaking down the feedthrough in vacuum using short, 1-ms pulses. After approximately 20 to 100 pulses, yoltage standuff on the vacuum side increased by at icast a factor of 2 . Breskdown princifally on the piessurized side of the feedthrough wuuld accur after conditioning. With 20 psig of $\mathrm{SF}_{6}$ on the pressurized side of the feedthrotgh. the following results were obtained:

\begin{tabular}{cc}
$\begin{array}{c}\text { Pulse length } \\
\text { (s) }\end{array}$ & $\begin{array}{c}\text { Breakdown iimit } \\
\text { (kV) }\end{array}$ \\
\hline 0.001 & 120 \\
0.1 & 100 \\
5.0 & 70 \\
\hline
\end{tabular}

Subsequent to the preliminary tests described here, the feedthrough was adapied for use on the TEXTOR tokamak at the Institute fo: Plasma Pbysies, KFA, Jullich, Gernany. The adaptation consisted priacipally of adding transiticn parts to mate with their connectors. To date, $130 \mathrm{~kW}$ has been applied to their antenas in vacuum using this nonoptimized reedihrough. With plasma, $500 \mathrm{~kW}$ has been applied sucseosfolly with 1-s pulses.

\section{TEXTOR FEEDTHROLGH UPGRADE}

A larger, more carefully designed feedihrough using the concept just described is eurrently being fabricated for use on TEXTOR. A diagram of this feedthrough is shown in Fig. 4. In this case input and output connections have 8 -in. outer conductors. Water cooling is provided along the fuil

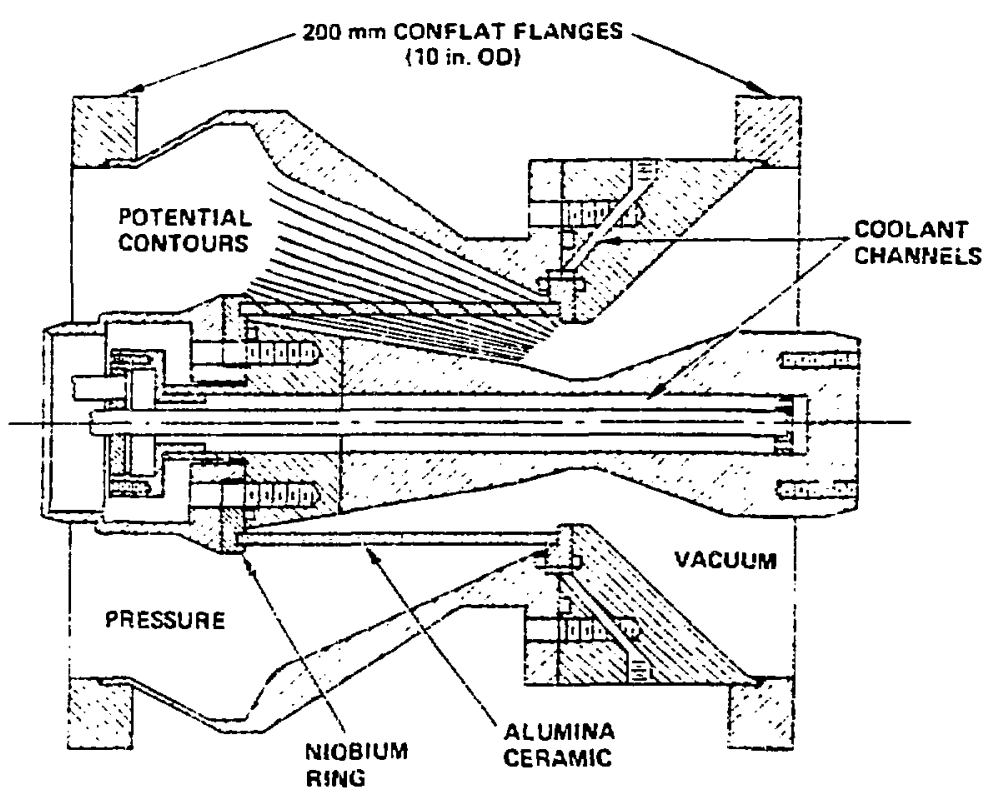

FIG. 4. Water-souled feedthrough design for the TEXTOR tokamak 
length of the inner conductor, but only the narrow postion of the outer conductor is water cooled. Potentia! contours superimposed on Fig. + are evenly snaced at reasonable intervils with no electrical stress soncentrations. Wave electrice fields are more nearly perpendicular to the ceramic surfaces than was the case for the test feedthrough described in the last section. Much more care has been isken to maintain a constant characteristic impeususce along the structure. Computer analysis indicates an IVSWR below 1.01:1 for frequencies below $200 \mathrm{MHz}$.

The ceramic in this case is a $94 \%$ pure $\mathrm{Al}_{2} \mathrm{O}_{3}$ brazed at each end to machined niobium rings. The rings are sindwiched between nanged parts on the inner and outer conductors. Metal O-ring vacuum suals are formed at the nicbium rings. The whole structure can be easily disasiembled for inspection or repiir.

Testing similar to that described in the last section will be performed for this feedthrough except that pulse lengths will he extended. High-current testing will be performed in addi. tion to high-voltage testing.

\section{CW FEEDTHROUGHS}

The ultimate goal of the ORNL feedthrough program is to deyelup i feedthruugh ispable of $\mathrm{cw}$ opcration. An integral part of this program is the construction of a cw testing facility to qualify candidate feedthroughs. Preliminary work hats been performed to design the $\mathrm{cw}$. feedthrough. Currently, the tapered conductor/cylindrical ceramic concepl is being considered. For this application a standard 9-in. coax connection is used that tapers duwn to 3.9-in. codx at the narrow end of the taper. The basic problem in the ciesign is devising an efficient cooling system for the conductors and the ceramic vacuum batrier. Finitc-element. thermal stress analysis of the feedthrough will determine in detail the effectiveness of the cooling system.

Preliminary estimates of overall cocling requirements have been obtained analytically. Total power dissipated in the tupered metal surfaces is given approximately by

$$
P_{m}=\left|\frac{1}{2} R_{3} I^{2}\right| \frac{l}{\pi\left(d_{1}-d_{0}\right)} \ln \left|\frac{d_{1}}{d_{0}}\right| .
$$

where $R_{s}$ is the surface resistivity, $d_{1}$ and $d_{0}$ are the diameters of the large and small ends, respectively, and $l$ is the taper length. A reasonable design requirement for current in the feedthrough is $I=2000 \mathrm{~A}$ at $100 \mathrm{MIF}$. For copper surfaces, this translates into $2680 \mathrm{~W}$ absorbed by the outer conductor and 6i90 $\mathrm{W}$ absorbed by the inner conductor. To carry away the heat, only $1-2$ gal/min are requared. Surface power density never exceeds $12 \mathrm{~W} / \mathrm{cm}^{2}$, implying only modest thermal transfer rates are required over all por. tions of the cunductors.

Power absorbed within the ceramic can be estimated from

$$
P_{\mathrm{c}}=\arg \epsilon_{\mathrm{r}} \tan \delta F_{0}^{2}
$$

where $\boldsymbol{F}$ is the ceramic voiume, $r$ is the relatr:e dickatrac constant of the cersmic, and tan $a$ is the loss tangent. T:1: field within the ceramic. $\Sigma_{0,}$ can be estimaled frem

$$
E_{0}=\frac{r}{t_{1}+t_{12} t_{2}} \text {. }
$$

where $V$ is the voltage across the conductors and $t_{1}$ and $t_{2}$ represent the thickness of the ceramic and the vacuum gap. respectively. A reasonable design requirement for the ferdihruugh voltuge empubility is $V=100 \mathrm{kV}$. This translates into $E_{0}=4770 \mathrm{~V} ; \mathrm{cm}$ for a ceramic $0.5 \mathrm{~cm}$ thick and a vacuum gap of $2.3 \mathrm{~cm}$. For a ceramic $15 \mathrm{~cm}$ icig. the total power absorbed will tien be approximately $567 \mathrm{w}$.

If no active cooling is provided for the ceramis, an upper bound on its ultimate temperature can be estimated by assuming the temperature is dic:aied only by attaisment of radiative equilibrium with the ouier conductor. An approxjmate expression for the temperature reached in this sittuation is given by

$$
T_{1}^{4}=\frac{q_{1}}{0 A_{1}}\left[\frac{\vdots}{e_{1}}+\frac{A_{1}}{A_{2}}\left(\frac{1}{e_{2}}-1\right)\right]+T_{2}^{3} .
$$

where $q$ is the power absorbed in the ceramic from the incident if power; $a$ is a constant equal in $2.4 \times 10^{-10}$ $\mathrm{W} / \mathrm{cm}^{2} /(\mathrm{K})^{4} ; e_{1}$ and $e_{2}$ are the emittances of the ceramic and copper oater conductor, tespectively; $A_{1}$ and $A_{2}$ are the areas of the ceramic ard outer conductor, respectively, and $T_{2}$ is the temperature of the outer conductor. For our exemflary cw feedthrough we find that the equilibriam iemperiture reached by the ceramic is on the order of $200^{\circ} \mathrm{C}$ if the outer conductol lersperature can be maintained near roon temperature.

Only a small amount of active cooling is required to bring the temperature of the ceramic down considerably. If one surface of the ceramic were cooled and if we assume. is : ver: case. that all of the power in the ceramic is absorbed on the opposite surface. the temperature drop across the thickness of the ceramic would be given by

$$
\Delta T=\frac{q t_{1}}{k t_{1}}
$$

where $k$ is the thermal conductivity. For an alumina ceramic with $k=0.18 \mathrm{~W} / \mathrm{cm} / \mathrm{K}$, we find $3 T=3.5^{\circ} \mathrm{C}$. For a water How over the ceramic surface of only 0.2 gal'min, the ceramic temperatuse will remain be!ow $\sim 14^{\circ} \mathrm{C}$.

It is anticipstev at the present time that water cooling of the ceranic will eventuali\} be usad. This will be done not just to carry away heat from fow absurption at ion cyelotron frequencies but also to prevent heating of the serainic by higher frequency microwaves coupled from other wave heating systems used cia the iusiun device. For example. sw. multimcgawatt lower hybrid current drive/healing and elsctron cyclutron heating may be used in flision devices. Theie 
schemes occur at multiple gigahertz. frequencies. Al these freyuencies, strong absorption can occur in ceramics. Water, being a strong absorber of microwaves, can be used not only to cool the ceramic but also to prevent the formation of mictowave standing waves within the ceramic. Water cooling can be easily introduced by using concentric ceramic cylinders with a small coolant passage between the cylinders. Use of hign-purity aluminas can also help to reduce the microwave power absorption within the ceramic.

\section{REFERENCES}

I. J. HOSEA and PLT GROUP, "PLT Cyclotron Range of Frequencies Heating Program," it Heating in Toroidal Plasmas (Proc. 4th Int. Symp., Rome, March, 1984), vol. 1, p. 261.

2. K. ODAJIMA et al., "Second Harmonic Heating Experiment in the HFT-2M Tokamak, in Hearing in
Toroidal Plasmas (Proc. 4 th Int. Symp., Rome, March, 1984), vol. 1, p. 243.

3. TFR GROLP. -ICRF Results on TFR at Megawatl Power Levels," Plasma Physics, 24, 61 (1982).

4. N. GREENOL iH and G. GROTZ, "High Yoltage RF Coaxial Yacuum Bushing Desizn Considerations," in Engineering Problems of Fusion Research (Proc. 9th Symp., Palmer House, Chicago, 1981). p. 842.

5. J. H. WHEALTON, R. J. RARIDON, D. J. HOFFMAN, T. L. OWENS, M. A. BELL, A. M. GOSWITZ, F. W. BAITY, and W. R. BECRAFT, "Theory of Feedlbroughs: Waveguide Transmissiod and Voltage Characteristics of High Power Current Feeds for ICRH" (proseedings of this meeting).

6. T. L. OWENS, D. J. HOFFMAN, F. W. BAITY, "Inductive Array Couplers For High Power ICRH," Bull. Am. Phys. Soc. 29 (8), paper 2 U20 (1984).

7. J. H. MULLEN, -High Power JCRH Launcher Design, Bull. Am Phys. Soc, 28 (8), paper ITi4 (1983). 